\title{
INTERCULTURALIDADE NA PERSPECTIVA BAKAIRI DO ENSINO DAS CIÊNCIAS DA NATUREZA NA ESCOLA INDIGENA
}

\author{
Edinéia Tavares Lopes ${ }^{\mathrm{i}}$ \\ Beleni Salete Grando ${ }^{\text {ii }}$ \\ Darlene Yaminalo Taukane $\mathrm{i}^{\mathrm{iii}}$ \\ Eduardo Maiawai Koni Tawanre ${ }^{\text {iv }}$ \\ Yasmin Lima de Jesus ${ }^{\mathrm{V}}$
}

\begin{abstract}
Resumo
Este trabalho objetiva investigar as possibilidades de construção de saberes da área das Ciências da Natureza no contexto da Educação Escolar Indígena, por meio do diálogo com temáticas do cotidiano indígena e que são práticas sociais relevantes para a constituição das identidades individuais e coletivas. Apresenta perspectivas metodológicas da etnografia e da pesquisa-ação. O trabalho resulta de uma pesquisa desenvolvida com o povo Bakairi da Aldeia Aturua, Território Indígena Bakairi - Brasil. Apontamos que a temática "Pinturas Corporais Bakairi" emerge como possibilidade significativa para a construção dos referidos saberes no contexto escolar pautado na educação intercultural. Defendemos que o direito à aprendizagem dos saberes dessa área não se restringe ao sentido universalista, mas se amplia e se (des/res)constrói em direção a efetivação da educação intercultural específica e diferenciada do e para o Povo Bakairi.
\end{abstract}

Palavras-Chave: Educação em Ciências; Educação Escolar Indígena; Educação Intercultural.

\section{INTERCULTURALITY IN THE BAKAIRI PERSPECTIVE OF THE TEACHING OF THE NATURAL SCIENCES IN THE INDIGENOUS SCHOOL}

\begin{abstract}
This work aims to investigate the possibilities of knowledge construction in the field of Natural Sciences in the context of Indigenous School Education, through dialoguing with indigenous daily themes that are relevant social practices to the constitution of individual and collective identities. It presents methodological perspectives of ethnography and action research. The work results from a research developed with the Bakairi people of the Aturua Settlement, Bakairi Indigenous Territory - Brazil. We point out that the theme "Bakairi Body Paintings" emerges as a significant possibility for the construction of such knowledges in the school context based on an intercultural education. We defend that the right to the learning of knowledges in this area is not restricted to the universalist sense, but it expands and (de / re) constructs towards to the realization of specific and differentiated intercultural education from and for the Bakairi people.
\end{abstract}

Keywords: Education in Sciences; Indigenous School Education; Intercultural Education. 


\section{O ensino de ciências da natureza na escola indígena: aproximações ao tema}

As diversas conquistas dos povos indígenas brasileiros em defesa do direito legal à educação escolar intercultural, bilíngue e diferenciada ganham notoriedade nas discussões e debates no cenário nacional a partir da Constituição Federal de 1988, no que diz respeito aos instrumentos legais e oficiais, e se aliam a gama de experiências que cada povo indígena acumula como prática educativa intercultural nas escolas, mas ainda assim, com grande conflito entre o que é legalmente direito e o que de fato é reconhecido como pertinente aos currículos escolares na perspectiva da comunidade e dos órgãos gestores nos municípios e estados.

O arcabouço legal e oficial desde a Constituição de 1988 garante os processos próprios de aprendizagens nas línguas indígenas e intentam proteger as manifestações das culturas populares, indígenas e afro-brasileiras, para em 2012 definir as Diretrizes Curriculares Nacionais para a Educação Escolar Indígena ${ }^{\text {vi }}$ (BRASIL, 2013).

Nesse interim, ocorreu em 1998 a publicação do Referencial Curricular Nacional para as Escolas Indígenas (RCNEI) e o estabelecimento das Escolas Indígenas no âmbito da educação básica por meio da Resolução n. 3 de 1999 do Conselho Nacional de Educação. O RCNEI 1998 destaca as características da escola indígena a partir da perspectiva de uma educação específica e diferenciada, sendo estas: comunitária, intercultural, bilíngue/multilíngue, específica e diferenciada (BRASIL, 1998).

A Resolução n. $3^{\mathrm{vii}}$ garante [...] normas e ordenamento jurídico próprios" e fixa "as diretrizes curriculares do ensino intercultural e bilíngue, visando à valorização plena das culturas dos povos indígenas e à afirmação e manutenção de sua diversidade étnica.

No que tange a diversidades de experiências nessa modalidade escolar, o que se observa é que elas têm demandado a (re/des) construção de práticas e produções acadêmicas que contribuam, dentre outros, para responder aos desafios colocados pelas diversas realidades indígenas brasileiras que buscam se consolidar no trânsito entre a lógica de produção e socialização de conhecimentos indígenas, os processos próprios de aprendizagens, denominados pedagogias indígenas, e a lógica ocidental. 


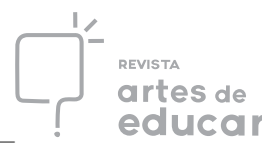

De tal modo, no que se referem ao ensino e aprendizagem dos saberes da Área das Ciências da Natureza ${ }^{\text {viii }}$ nas escolas indígenas, incursões teóricas nos levam a afirmar que, esses saberes, ao serem trabalhados sob a ótica da Ciência Ocidental, colocam a necessária revisão do pensamento colonial, que ao deslegitimar, silenciar e excluir outras formas de saberes que não seja a ocidental, coloca o saber científico como forma universalmente válida de produzir e socializar conhecimentos, impondo-se de forma autoritária e eurocêntrica aos saberes e práticas dos povos autóctones (LOPES, COSTA, MOL, 2014; LOPES, 2015; ROSA e LOPES, 2018).

Para além dos dilemas nos quais se situam a área, ou os saberes da área e, sobretudo, ao complexo desafio colocado pela questão da relação entre distintas formas de produzir saberes, reflexo dessas diferentes dimensões culturais, o que buscamos neste trabalho se estabelece num movimento dialógico, caracterizado pelo dissenso e pelo consenso, por avanços e recuos, mas, sem perder de vista a interculturalidade, que como afirma Fleuri (2003, p.17) é a possibilidade de respeitar as diferenças e de integrá-las em uma unidade que não as anule.

Com isso, não negamos ou propomos a exclusão do saber dessa área, mas, defendemos a necessidade de mais investigações que possibilitem trabalhar com as diversas perspectivas de explicação do mundo e, particularmente, as produzidas pelos povos indígenas e pela Ciência Ocidental, problematizando-as como formas distintas de aprender e ensinar no e sobre o mundo partilhado (CALDERONI, NASCIMENTO, 2012) por diversas formas de viver e estar, ou ainda, como assinala Chassot (2003, p. 91) reconhecer que a Ciência pode ser considerada como uma linguagem construida pelos homens e pelas mulheres para explicar o nosso mundo natural, portanto, como uma das construções humanas, ela também é mutável e falível.

Desse ponto de vista, apontamos, antes de tudo, que os mais de 300 povos indígenas brasileiros têm suas culturas e histórias em permanente movimento, portanto é necessário, não só estudar os modos de apropriação e relação com a educação escolar de cada povo indígena (LOPES, 2015), como também, as condições históricas e culturais que possibilitaram a produção dos conhecimentos reconhecidos como relevantes para a comunidade ontem e hoje. 
Tendo essas reflexões iniciais como ponto de partida, neste texto trazemos de forma sistematizada os resultados de uma pesquisa em processo de consolidação na prática pedagógica intercultural na Escola do Povo Bakairi, no ensino da área das Ciências da Natureza, buscando superar a visão científica e monocultural dessa área, a fim de promover uma reflexão sobre como esses saberes e práticas podem trazer elementos para se pensar e significar o currículo na perspectiva indígena.

A pesquisa que orienta esse texto tem por objetivo investigar as possibilidades de construção de conhecimentos escolares das Ciências da Natureza no contexto da Educação Escolar Indígena (EEI), por meio do diálogo com temáticas do cotidiano do Povo Bakairi, em Mato Grosso, Brasil.

\section{Do contexto sociocultural, histórico e metodológico da investigação}

Este texto foi subsidiado pela pesquisa de doutoramento e pós-doutoramento da primeira autora realizada junto ao povo Kurâ-Bakairi de Paranatinga, no estado de Mato Grosso, Brasil, cujo foco foi a EEI, tratando da produção de conhecimentos científicos escolares no âmbito da inserção da temática indígena no currículo das escolas não indígenas e na produção de material didático para o ensino das Ciências Naturais na EEI. A fase dos estudos de pós-doutorado contemplou ainda o projeto de iniciação científica (CNPq) e de popularização das Ciências (FAPITEC/SE/FUNTEC/CNPq), sob sua coordenação, e dialogou com os saberes e práticas dos autores kurâ-bakairi ao mesmo tempo em que busca refletir os estudos desenvolvidos junto ao grupo de pesquisa Corpo, Educação e Cultura (CNPq). Esta investigação ainda está vinculada ao projeto "Educação em Ciências na perspectiva intercultural: investigando e construindo possibilidades" Financiado pelo CNPq, Edital Universal 01/2016, Processo no 429682/2016-6.

A pesquisa tem como pressuposto a abordagem qualitativa, com fase caracterizada pela perspectiva etnográfica e pela pesquisa-ação (BOGDAN, BIKLEN, 2003; FLICK, 2009). Essas fases se articulam, na medida em que trazem dados necessários à compreensão da problemática. 
A etapa ora apresentada teve como recorte o estudo das pinturas corporais e o ensino de Ciências da Natureza, que, para a escrita final deste texto, passou pelo crivo crítico de pesquisadores e lideranças do próprio povo Kurâ-Bakairi, coautores deste trabalho ${ }^{\mathrm{ix}}$.

Os Bakairi, como são conhecidos na literatura sobre os povos ameríndios, atualmente habitam dois territórios mato-grossenses, delimitados em: Terra Indígena Santana, localizada no município de Nobres; e Terra Indígena Bakairi (TIB), que está demarcada em sua maioria no município de Paranatinga e uma pequena parte em Planalto da Serra. Os dados da pesquisa que trazemos neste texto foram coletados em uma das 10 aldeias existentes na atualidade na TIB.

Os Bakairi se autodenominam Kurâ, que remete à ideia de "nosso povo, aquilo que é inerente do povo Kurâ", e sua língua pertence ao tronco Karib e praticamente todos os KurâBakairi são bilíngues. (TAUKANE, 1999, p. 35). Conforme a autora, a escola foi inserida na TIB em 1922 e somente a partir de 1985 foi assumida pelos professores bakairi.

Atualmente todos os professores da TIB são bakairi e quase todos com formação em cursos específicos para professores indígenas. A educação escolar ofertada na TIB atende da Educação Infantil ao Ensino Médio, sendo que das quatro escolas construídas nesse território, duas ofertam o Ensino Médio. Muito estudantes egressos dessas escolas estudam ou estudaram, sobretudo em nível de graduação, em universidades públicas brasileiras (UNEMAT, UFMT, UnB, UFPR e UFSCar) e continuam a buscar ampliar a formação acadêmica em nível de pós-graduação.

\section{Das relações com o ensino de ciências da natureza nas demais escolas brasileiras}

As experiências e investigações na Educação em Ciências na EEI brasileira são relativamente novas, dado o fato de que essa modalidade de ensino somente iniciou como possibilidade na perspectiva aqui apresentada a partir da Constituição de 1988, o que promoveu e demandou a ampliação das experiências e os estudos da educação escolar dos povos indígenas, mas especificamente, o enfrentamento da concepção monocultural pautada na ciência como única verdade a se consolidar no campo educacional brasileiro. O desafio, portanto, supera os limites da educação escolar indígena, pois a perspectiva de compreender a 


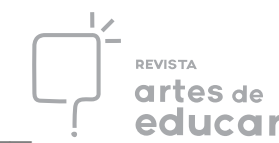

ciência como única verdade e prática social que deve orientar a prática pedagógica é ainda recorrente nas pedagogias que orientam a construção dos currículos escolares em todo o país.

Isto significa que, de certo modo, também é nova essa perspectiva de pesquisa de Educação em Ciências, quando comparada com as outras áreas da Educação. Ao recorrermos a análise das pesquisas nessa área, identificamos que continuam presentes neste campo de estudo a fragmentação dos conhecimentos, a a-historicidade, a reprodução do livro didático e o não vínculo com a realidade sociocultural dos alunos, caracterizando-se de maneira geral, a predominância do modelo de ensino de Ciências presente até a atualidade nas escolas brasileiras (ZANON; PALHARIN, 1995; FUMAGALLI, 1998; LORENZETTI; DELIZOICOV; 2001; OVIGLI; BERTUCCI; 2009; CACHAPUZ, 2011; CHASSOT, 2001; 2003; LIMA e LOPES, 2013).

Certamente, tais características não dão conta dos objetivos de propiciar aos cidadãos conhecimentos e desenvolvimento de capacidades e habilidades necessárias à formação cidadã que possa compreender e intervir de forma crítica em sua realidade social. Por outro lado, as críticas pelas quais a ciência tem sido submetida a partir do século XX impactam as significações sobre currículo, particularmente a sua identificação e legitimação dos saberes científicos nos contextos educacionais de um país multiétnico como o Brasil.

Nesse sentido, propõe-se a compreensão da Ciência como uma das linguagens para falar sobre o mundo, como aponta Chassot (2003), ou, no campo estudos sobre currículo, como jogos de linguagem com os quais significamos o mundo (LOPES, MACEDO, 2013, p. 153). Essa compreensão dialoga com o que apontam os colaboradores Bakairi desta pesquisa sobre o significado de Ciência:

[...] Para nós, enquanto indígenas, como que a gente enxerga a ciência, ela é institucionalizada através das universidades, a pessoa, o aluno é preparado ou ele escolhe um determinado área para se especilaizar, pode ser área de ciências exatas ou humanas como dizem, por exemplo, pode ser biólogo, o que ele escolher [...] ele tem o conhecimento das tecnologias, dos laboratórios" Enquanto que nós, os indígenas temos a nossa ciência de forma coletiva, ela é compartilhada por vários membros da nossa sociedade, nós aprendemos a fazer e aprender alguma coisa a partir da nossa necessidade, como por exemplo construir uma casa, fazer uma rede, conhecer as plantas medicinais, os nossos saberes tradicionais acontecem na 
maioria das vezes no nosso cotidiano, se dá na observação, na prática do fazer. (Pesquisador Colaborador, 2016).

Assim sendo, contextualizar e problematizar o processo de ensino e aprendizagem da área no âmbito da EEI parece-nos desafiador, já que demanda não negar que ele é, de certa maneira, herança do um modelo de ensino de Ciências da Natureza praticado nas demais escolas brasileiras, mas, ao construir, no contexto escolar indígena, novas significações curriculares, pode contribuir para repensar e, quiçá, ressignificar esse ensino nas demais escolas brasileiras.

Espera-se que esse estudo contribua para os primeiros passos para essa ressignificação dos currículos gestado pela EEI. De tal modo, reconhecemos que os saberes e práticas sociais de um povo autóctone, ao ser transformado em conteúdo de ensino e prática pedagógica, podem contribuir para superar a realidade observada em algumas escolas indígenas (e também não indígenas), que, como dito, herda características do ensino das Ciências da Natureza e ainda está consolidado nos currículos das demais escolas brasileiras.

O desafio de superar essa herança eurocêntrica das ciências que se impõem nos currículos escolares é reconhecido pelos professores indígenas, como afirma um dos colaboradores Kurâ-Bakairi:

Na década de 90 se falava muito numa educação diferenciada para os povos indígenas mas atualmente essa proposta não dá conta das realidades das escolas indígenas, para que educação escolar indígena seja diferenciada, primeiro impasse é o material didático nas escolas indígenas, até hoje as escolas indígenas recebem o material didático distribuído pelo governo, eu por exemplo, participei da elaboração do RCNEI, naquele momento esse referencial foi importante mas hoje, eu tenho clareza que temos que formar escritores, pessoa que escreve e ilustrador para termos materiais didáticos de acordo com as nossas realidades, para que tenhamos de fato uma educação diferenciada (Pesquisador Colaborador, 2016).

Em seu argumento, tem a clareza desse desafio e problematiza com propriedade as dimensões dessa imposição colonizante dos saberes da escola que não são facilmente superados: [...] os povos indígenas são muitos ricos na contação de seus mitos, suas estórias, 
mas como transformar esses conhecimentos numa escrita? Uma vez que, tradicionalmente esses mitos são contados oralmente (Pesquisador Colaborador, 2016). Problematiza, assim:

Tem muitos mitos que podem ser trabalhados nas escolas, mas se transformar esses mitos em escrita estaremos dando formatos dos personagens. E eu me pergunto: Que formatos que daremos para esses personagens? Se os personagens dos mitos sempre estiveram apenas nas imaginações de quem conta e de que ouve as estórias? Tem que ter consenso da comunidade para que esses personagens se materializem. Como imaginar as onças em forma de gente, se antes, tudo era gente, planta e animais. (Pesquisador Colaborador, 2016).

Como resposta aponta as possibilidades das parcerias, do trabalho conjunto, mas que ao se promover uma proposta nessa perspectiva ela deve reconhecer antes, o potencial criativo e intelectual do professor indígena: [...] a gente só vai ajudando, você na sua área, eu na minha área. Enquanto isso não acontecer, não teremos material didático diferenciado. $O$ RCNEI foi uma tentativa e hoje já está superado, não dá conta (Pesquisador Colaborador, 2016).

Assim sendo, neste trabalho, permeiam reflexões que buscam articular os saberes específicos do povo Bakairi e os da ciência, necessários à revisão dos conteúdos que se consolidaram, no ensino-aprendizagem, na educação escolar, uma prática social/pedagógica colonizadora, que desqualifica os saberes locais que constituem a cosmovisão ameríndia e suas práticas que salvaguardam a vida nesse contexto socioambiental.

Nossa proposição para o ensino na perspectiva intercultural se pauta no conteúdo de ensino de Ciências - O corpo e as propriedades químicas dos materiais que o identificam - as pinturas corporais bakairi. Esse conteúdo de ensino se constitui assim, como catalisador de saberes e práticas que convertam em uma prática pedagógica do Ensino das Ciências da Natureza, passa pela sensibilização de que, a retirada das especificidades de seus contextos culturais de produção pode levar à imposição de valores externos que desconsideram todo o legado cultural e tecnológico dos povos indígenas brasileiros.

O corpo, no processo histórico de constituição da ciência, vem adquirindo lugar de destaque como objeto de investigação de distintos campos disciplinares. Dentre estes se destacam, particularmente, a Educação Física, 
onde o corpo se constitui elemento central da área e as Ciências Sociais, por ser considerado um objeto tradicional de investigação. $\mathrm{Na}$ contemporaneidade, o corpo vem sendo estudado de modo interdisciplinar, porém vale ressaltar que esses campos ao compartilharem o corpo e as práticas a ele relacionadas, como objeto de estudo, apresentam distintas perspectivas de análise [...] com base em conceitos que emanam de tradições teóricas distintas e, em algum aspecto, complementares. (ALMEIRA; ALMEIDA; GRANDO, 2010, p. 60).

Com isso, ao considerarmos, como afirmamos anteriormente, a ciência como mais um dos discursos, reconsideramos que nos jogos de linguagem para os Bakairi o conteúdo de ensino dessa deva se pautar em uma linguagem que lhes dão significados de mundo (LOPES, MACEDO, 2013, p. 153).

$\mathrm{Na}$ perspectiva dos estudos empreendidos com os povos indígenas e os estudos do corpo como centralidade da pessoa, Grando $(2004$; 2014) afirma que as pinturas corporais para um povo indígena são antes uma construção social histórica que possibilita a marca de identidade no corpo de cada pessoa desde o nascimento, sua família, seu clã, sua idade, seu gênero, enfim, seu lugar na sociedade a qual está sendo inserida e se constituindo como sujeito.

O corpo, nessa dimensão, é a centralidade da pessoa para os povos indígenas e por isso mesmo, as pinturas corporais são antes, formas simbólicas que possibilitam a identificação de cada um no mundo, onde será reconhecido e se reconhecerá como parte constitutiva dele e do seu grupo. O mundo para cada povo indígena é sua cosmologia que se constitui de forma amalgamada com a natureza (GRANDO, 2004).

A pintura corporal a partir dessa compreensão de corpo para os povos indígenas é compreendida como uma prática corporal, pois explicita em si uma prática social relevante para um determinado grupo que a reconhece e lhe dá significado, portanto, [...] manifesta sempre sentidos e significados coletivos e especificos de quem a pratica e como tal, ao ser associada a contextos diferentes e praticada por sujeitos diferentes, adquire [...] significados e sentidos diferentes também de acordo com os contextos, o tempo e o espaço onde ocorrem [...] de acordo com quem delas participa, seja como praticante ou espectador (GRANDO, 2004, p. 60). 
Com efeito, desde a primeira descrição etnográfica dos Bakairi, realizada em 1884 por Karl Von Den Stenein (BARROS, 2003), suas pinturas corporais foram evidenciadas por serem práticas sociais relevantes para esse povo desde sempre. Assim, a forma como o KurâBakairi desenvolveu a tecnologia capaz de marcar os corpos expressa sua história e cultura específica.

Com isso, trazemos neste texto as "Pinturas Corporais Kurâ-Bakairi" como catalisador de saberes e práticas que convertam em uma prática pedagógica que permita também possibilidades de construção de conhecimentos das Ciências da Natureza, por meio do diálogo com os conhecimentos do cotidiano desse povo. Portanto nesse diálogo a proposta é fugir das análises binárias: superioridade e inferioridade, dominação e subordinação, primitivo e moderno, desenvolvidos e subdesenvolvidos, ciência ou não ciência (no sentido do que é válido ou não válido). Buscamos inscrever nossas reflexões em possibilidades de significações, de negociação: onde há espaços para a articulação de elementos antagônicos ou contraditórios, que produzem lugares e objetivos híbridos de luta; os entre-lugares, aos moldes de Bhabha (2003).

\section{Dos saberes e fazeres tradicionais e dos saberes e fazeres da ciência}

A pintura corporal é a primeira escrita e nela o homem e a mulher marcam suas identidades, suas crenças e buscam suas proteções pelos pertencimentos ao Outro, seja no mundo dos vivos ou de outras dimensões cosmológicas e míticas. É uma forma de linguagem que acreditam que é reconhecida em todas as dimensões da vida por expressar no corpo cada pessoa ao seu mundo. Essa marcação do corpo evidencia, ao mesmo tempo, que somos todos iguais, humanos e, diferentes, pois é nele próprio que podemos nos tornar únicos, seja por meio de rituais, por marcas temporárias ou permanentes, podemos nessas ser reconhecidos e diferenciados no próprio grupo e nos demais, pois é no corpo que cada pessoa vive o seu tempo e seu espaço social (GRANDO, 2009).

Na memória dos mais velhos os Kurâ-Bakari vieram no mundo com essas práticas culturais marcadas em seus corpos que se mantém ao serem repassadas de geração a geração como saberes de tempos imemoráveis, por meio dos desenhos e dos nomes que diferenciam os grafismos das pinturas de homens, de mulheres e de crianças (Figura 1). 


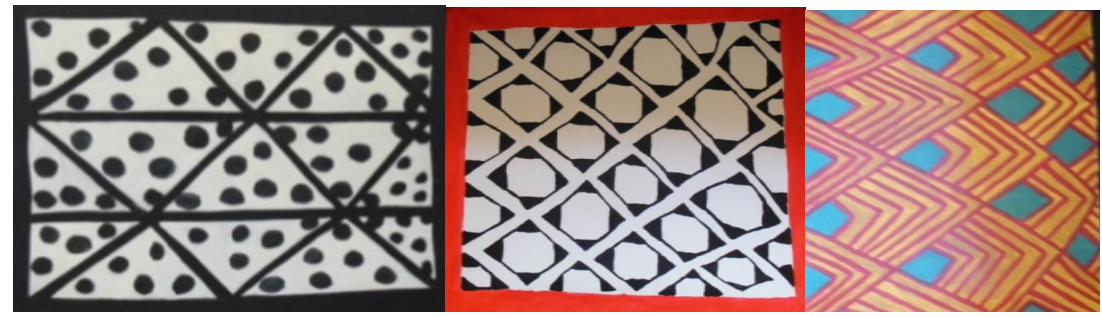

Figura 1- a) Xurui (peixe pintado) pintura de crianças, b) Tuturein (Jiboia) pintura dos homens, c) Semimu (Morcego) pintura das mulheres.

Fonte: Desenhos de Kaya Agari, Exposição Kurâ-Bakairi Yakuigady e Kywenu, Museu de Arte de Mato Grosso, 2015.

Além das insígnias kurâ-bakairi que marcam os corpos ontem e hoje, as pinturas sempre evidenciaram as tecnologias dominadas pelo povo que a produz, pois, para além dos rituais, por meio delas o corpo é protegido frente aos desafios cotidianos (insetos, raios solares) e outros inimigos do mundo dos vivos e dos mortos.

Os Kurâ-Bakairi ao fazer uso da natureza para garantir a produção das pinturas corporais produzem saberes e práticas sociais ancestrais e, para isso, o urucuzeiro e o jenipapeiro, plantas presentes em seus territórios são a fonte de produção de suas pinturas. A pintura assim, além de falar da cultura de um povo, traz o seu contexto ambiental no mundo.

O urucuzeiro é conhecido no gênero de discurso científico por Bixa orellana L., o que significa que é um arbusto tropical pertencente à divisão Magnoliophyta conhecida como Angiospermas, e pode apresentar tamanhos variados com flores e frutos. As sementes do urucum apresentam em sua película externa (cobertura carnosa, denominada pela narrativa científica de arilo da semente) uma substância vermelha denominada bixina (RENHE, 2009).

A tecnologia Kurâ-Bakairi para a extração da bixina (Figura 2a) é a maceração das sementes do urucum com as mãos. Essas sementes ao serem maceradas em contato com a água formam uma pasta na qual os Kurâ-Bakari, aos poucos, adicionam óleo vegetal que também produzem da flora regional (atualmente também usam óleo industrializado). Essa pasta é deixada em repouso até apresentar consistência de tinta. Geralmente, essa tinta é feita pelos membros da comunidade um dia antes de usarem. 
A Genipa americana L., conhecida popularmente como jenipapeiro, pertence à família Rubiaceae (família do café) e é uma árvore nativa do Brasil que pode chegar a $20 \mathrm{~m}$ de altura. O fruto de jenipapo, enquanto verde, produz, pelo processo de oxidação, um corante com tom azul escuro. Oxidação é uma reação que ocorre quando a jenipina presente na polpa do fruto do jenipapo entra em contato com o oxigênio do ar (STRINGHETA; SILVA, 2008). Nesse processo, ocorre o escurecimento da polpa do fruto pela presença da jenipina oxidada.

Para a extração do pigmento jenipina (Figura 2b), esse povo corta em pequenos pedaços ou rala a polpa do jenipapo. Em seguida leva ao fogo até que a coloração dessa mistura fique escura e sua consistência mais firme, no ponto de fazer as pinturas. Alguns grupos indígenas ainda adicionam o carvão a essa mistura procurando deixá-la mais escura.

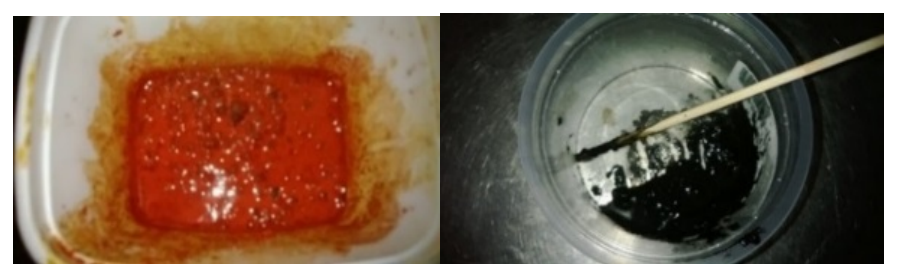

Figura 2- a) corante vermelho extraído do urucum, e b) corante azul-preto extraído do jenipapo. Fonte: Arquivo do Projeto, 2013.

Podemos constatar que o povo Kurâ-Bakairi ao fazer suas tintas, produz diversos conhecimentos sobre a manipulação dessas plantas e das substâncias nelas envolvidas. De maneira geral, eles identificam a fonte do pigmento, substâncias necessárias para essa extração, os procedimentos e condições para extração. Para isso foram necessários anos de observação e manipulação deliberada desses materiais, portanto, os saberes produzidos não podem ser obra do acaso, mas sim de reflexões deliberadas sobre as experiências da vida, refletidas e validadas na prática (GEERTZ, 2006). Segundo o Pesquisador Colaborador:

$[\ldots]$ o nosso conhecimento [...] que é coletivo [...] para os povos indígenas a ciência está no dia a dia da pessoa, por exemplo. Considero meu pai como um detentor de um conhecimento sobre das estrelas, ele tem capacidade de fazer a leitura do céu, todas aquelas histórias que os antepassados contavam lá no céu tem três estrelas enfileiradas, essas estrelas são conhecidas como as filhas do kwamoty, ele sabe tudo na nossa língua [...] pela leitura que ele faz, ele fala que através das estrelas pode ser contada os mitos, no céu 
estrelado podemos enxergar uma tamanduá, uma onça, e uma lagoa conhecido como saimu, tem vários personagens. (Pesquisador Colaborador, 2016).

Para ele, a ciência de seu povo está presente no dia a dia. Sua fala explicita um entre lugar, aos moldes de Bhabha (2003), pois, considera em sua narrativa, mesmo tendo se referido a ciência dos povos indígenas, que a ciência é um divisor de águas entre os conhecimentos do branco e o nosso conhecimento [...] que é coletivo [...].

É nessa perspectiva do entre-lugar, dos movimentos pequenos, internos e externos que a decolonização do currículo pode ocorrer. Interno na medida em que constatamos que o que temos ainda como práticas do ensino das Ciências da Natureza não dão conta de responder as atuais demandas da educação escolar indígena. Externo, pois podem descontruir nossas convicções de que há uma verdade universal, a verdade do conhecimento científico ocidental. Além disso, cabe a própria área construir entendimento que de suas próprias explicações apresentam verdades transitórias.

Logo, em uma perspectiva intercultural crítica, há de se considerar as complexidades e as ambivalências produzidas no encontro com os diferentes saberes próprios ao processo educativo (CALDERONI; NASCIMENTO, 2012).

De tal maneira recorrendo ao sentido de Fleuri (2012, p. 16): [...] a interação educacional intercultural - no sentido dialógico, crítico e problematizador - requer uma constante atitude de escuta do outro, de autocrítica e de reconfiguração epistemológica do olhar e entender a alteridade.

Algumas reflexões levantadas pelo interlocutor Kurâ-Bakairi, nessa pesquisa, ao nos referirmos às diversas utilizações pela indústria ${ }^{\mathrm{x}}$ dessas frutas e pigmentos delas extraídos, explicitam o necessário diálogo intercultural crítico e, portanto, problematizador, pois ao relembrar de uma reunião entre professores Kurâ-Bakairi, o mesmo menciona uma fala que expressa o consenso entre os presentes: [...] nós podemos manter, preservar as nossas tecnologias. Para explicitar melhor, acrescenta a sua compreensão de como a ciência se evidencia nas tecnologias Kurâ-Bakairi:

[...] como um indígena calcula exatamente o desenho, o triângulo de uma peneira e de uma apá... como divide esses talos, matematicamente para que 
faça aquele desenho [...] qual o segredo desse desenho. A gente viu que nos temos nossas tecnologias [...] e podem ser estudados por nós [...] podemos ensinar a fazer o artesanato usando os cálculos das nossas tecnologias. (Pesquisador Colaborador, 2016).

Para ele, a partir de nossas tecnologias, tem como ensinar matemática, fazer esses cálculos, como fazia o avô:

[...] fazia a peneira, ele começava com quatro talinhos e vai colocando mais quatro [...] é a multiplicação do quatro nesse tear, nesse entrelaçar dos talinhos [...] é uma ciência, como chega a emborcar esse material, uma pessoa leiga não vai conseguir fazer porque não tem os cálculos, não conhece não tem esse domínio, dessa tecnologia (Pesquisador Colaborador, 2016).

Compreende-se assim, que por meio da produção das tintas os Kurâ-Bakairi produziram saberes e fazeres, ou em outras palavras, produzem seus conhecimentos sistematizados e suas tecnologias tendo como referência a exploração e domínio tecnológico dos recursos naturais disponíveis em seu território.

Porém, os diversos saberes tradicionais dos povos ameríndios foram e são apropriados pela ciência, e por consequência, pela escola, negando-lhes a autoria, e como afirma Classot (1993), ao ser legitimados como verdade dessa lógica de produção. Assim, refletir criticamente sobre a ciência e a tecnologia (ocidental), parece-nos necessário, enquanto forma de transitar de forma crítica entre as formas de produção dos saberes discutidos neste texto. Tal reflexão, no entanto, não se estabelece numa proposição de antagonismos entre o bem e o mal, mas no entendimento de quais respostas (transitórias, circunscritas) cada um tem traduzido em saberes e fazeres.

Ademais a proposta de abordar as pinturas corporais kurâ-bakairi não se pauta no sentido de revitalizar a cultura, ou trazer fragmentos da cultura kurâ-bakairi para fazê-los visíveis nas aulas em comparação com outros saberes legitimados pela escola, pois, sendo essas pinturas elementos constitutivos da cultura kurâ-bakairi na atualidade, se insere na proposição de ensinar por meio da cultura a ciência e a realidade sociocultural de Mato Grosso. 
Nesse pensamento, o professor Kurâ-bakairi não assume o papel de facilitar a educação intercultural, mas de promover em sala de aula com o ensino da ciência, a educação intercultural na perspectiva kurâ-bakairi, como evidencia os direitos constitucionais dos povos indígenas do Brasil.

Com isso, esse trabalho é uma possibilidade de apontar caminhos que podem ser assumidos por outras práticas sociais, outras produções de conhecimentos e tecnologias que imprimem o reconhecimento das pedagogias indígenas. De tal modo, em alusão a Bhabha (2003) e a Fleuri (2012), cabe ao professor indígena a complexa tarefa da construção de conhecimento no "entre-lugar" do currículo e da escola, construído e constituído por relações dialógicas, nas quais as diferenças são respeitadas, reconhecidas e integradas, sem as anularem. Esse desafio, no entanto, exige que as instituições educacionais e os pesquisadores também se disponham a essa aprendizagem.

\section{Considerações finais}

Com este trabalho não vislumbramos dar uma resposta aos dilemas enfrentados no ensino das Ciências da Natureza nas escolas indígenas, mas apontar possibilidades no diálogo intercultural com a cultura indígena, como um direito dos estudantes indígenas ao acesso, às diferentes formas de interpretar e falar sobre o mundo, inclusive a partir da cosmologia dos seus ancestrais reconhecidos pelos saberes e práticas também na educação escolar.

Com isso, nos colocamos ao lado dos que almejam a transformação das práticas escolares na qual a educação intercultural não seja uma tarefa adicional, a margem do currículo, mas uma prática social que promova o reconhecimento de que no mundo partilhado vivido por todos os humanos, os saberes e as práticas são formas de conhecer e viver válidas e pertinentes para ensinar e aprender viver juntos. A perspectiva da educação intercultural não é uma tarefa resolvida com uma ou outra prática educativa, mas um processo que pode ser desencadeado também ao nos propormos aprofundar os conhecimentos, relativizando as verdades consolidadas de forma monocultural e autoritária no contexto escolar.

As pinturas corporais kurâ-bakairi, nos apontam, a partir dessa pesquisa, como uma significativa temática para possibilidades de construção de conhecimentos escolares das 
Ciências da Natureza no contexto da Educação Escolar Indígena, pois além de trazer o cotidiano desse povo para o processo educativo da área, possibilita a articulação entre as diferentes áreas numa perspectiva interdisciplinar, rompendo as fragmentações que persistem na organização curricular da maioria das escolas brasileiras.

Contudo, o trânsito entre essas diferentes lógicas de produção de saberes demanda colocar no centro dessa discussão a pessoa, que como vimos, é o corpo, e ele sendo o centro do conhecimento e da nossa própria identidade, podemos relativizar os conhecimentos a partir das formas como nele nos identificamos, nos diferenciamos e com ele superamos as visões monoculturais e etnocêntricas em direção ao que a Educação Indígena nos propõe, a Educação Intercultural, pois se cada corpo fala de si com suas pinturas, essas dependem do Outro para existirem e serem nele reconhecidas ao reconhece-lo. A dependência social e afetiva do Outro, é assim, o que nos parece estar explicitado nesse processo de aprender e ensinar da pedagogia indígena intercultural, onde a escuta, a observação e a relação sistêmica e epistêmica com a natureza é social.

\section{REFERÊNCIAS}

ALMEIDA, A. J. M. De; ALMEIDA, D. M. F. De; GRANDO, B. S. As práticas corporais e a educação do corpo indígena: a contribuição do esporte nos jogos dos povos indígenas.

Revista Brasileira de Ciências do Esporte, Florianópolis, v. 32, n. 2-4, p. 59-74, dez. 2010.

BARROS, E. P. Os Filhos do sol: História e Cosmologia na Organização Social de um povo Karib: Os Kurâ-Bakairi. São Paulo: EdUSP, 2003.

BHABHA, H. O local da cultura. Belo Horizonte: Ed. UFMG, 2003.

BOGDAN R. C., BIKLEN S. K. Investigação qualitativa em educação. Porto: Porto Editora; 2003.

BRASIL. Ministério da Educação. Diretrizes Curriculares Nacionais Gerais da Educação Básica. Brasília: MEC, SEB, DICEI, 2013.

CACHAPUZ, A. et al. Importância da Educação Científica na Sociedade Actual. In:

CACHAPUZ, A. et al. A necessária renovação no ensino de ciências. São Paulo: Editora Cortez. 2005. 
CALDERONI, V A M O; NASCIMENTO, A C. Saberes tradicionais indígenas, saberes ocidentais, suas intersecções na educação escolar indígena. Visão Global, Joaçaba, v. 15, n. 1-2, p. 303-318, jan./dez. 2012.

CHASSOT, A. I. Alfabetização Científica: questões e desafios para a educação. 2 ed. Ijuí: Ed. UNIJUÍ, 2001.

. Alfabetização Cientifica: Uma possibilidade para a inclusão social, Rev.

Brasileira de Educação, n²2, Jan/Fev/Mar/Abr, 2003.

. Catalisando transformações na educação. Ijuí: Ed. UNIJUÍ, 1993.

FLEURI, R. M. Educação Intercultural: descolonializar o poder e o saber, o ser e o viver.

Visão Global, Joaçaba, v. 15, n. 1-2, p. 7-22, jan./dez. 2012.

FLEURI. R. M. Intercultura e educação, n. 2, 2003. Disponível em:

$<$ http://www.scielo.br/pdf/rbedu/n23/n23a02.pdf >. Acesso em: 21 jul. 2012.

FLICK, U. Qualidade na pesquisa qualitativa. Porto Alegre: Artmed; 2009.

FUMAGALLI, L. O ensino das Ciências Naturais no nível Fundamental da Educação Formal: Argumentos a seu favor. In: WEISSMANN, Hilda (Org). Didática das ciências naturais: contribuições e reflexões. Porto Alegre: ArtMed, 1998.

GEERTZ, C. O saber local: novos ensaios em antropologia interpretativa. Tradução de Vera Melo Jocelayne. 8ed. Petrópolis, RJ: Vozes, 2006.

GRANDO, B. S. (org.). Corpo, Educação e Cultura: práticas sociais e maneiras de ser. Ijuí, RS: Ed. Unijuí, 2009.

GRANDO, B. S. Do Corpo e da Cultura: indícios da realidade na perspectiva intercultural. Revista Arquivos em Movimento, Rio de Janeiro, Edição Especial, v.10, n.1, p.138-154, jan/jun 2014.

LOPES, A, C.; MACEDO, E. Currículo e cultura: o lugar da ciência. In: Temas de pedagogia: diálogos entre didática e currículo. LIBÂNEO, J. C.; ALVES, N. (orgs.). São Paulo: Cortez, 2012.

LOPES, E. T.; COSTA, E. V.; MOL, G. S. Educação em ciências e ensino de química: perspectivas para a pesca com o timbó na voz de alunos de uma escola indígena brasileira. Revista Fórum Identidades, v. 15, p. 1-27, 2014.

LOPES, E. T. Um olhar acerca das relações entre sujeitos Baikairi, a escola indígena e os conhecimentos científicos escolares. In: SOUZA, D. N. e SILVA, V. A. A questão do sentido e pesquisas em ensino de ciências e matemática: uma homenagem a Bernard Charlot. São Paulo: Editora Livraria da Física, 2015, v. 1, p. 401-442. 
LOPES, E. T. Ensino-Aprendizagem de Química na Educação Escolar Indígena: O Uso do Livro Didático de Química em um Contexto Bakairi. Química Nova na Escola, v. 37, p. 249256, 2015.

LORENZETTI, L.; DELIZOICOV, D. Alfabetização científica no contexto das séries iniciais. Ensaio - Pesquisa em Educação em Ciências. v. 0 3, nº 1, 2001.

OVIGLI, D. F. B. e BERTUCCI, M. C. S. A formação para o ensino de ciências naturais nos currículos de pedagogia das instituições públicas de ensino superior paulista. Ciência e cognição, v. 14, n. 2, p. 194 - 209, jul., 2009. Disponível:

$<$ http://www.cienciasecognicao.org $>$. Acesso em: 30 de Junho de 2010.

SANTA ROSA, S. C.; LOPES, E. T. Tendências das publicações brasileiras sobre a formação de professores indígenas em ciências da natureza. Amazônia (Revista de Educação em Ciências e Matemática), v. 14, n 32, p. 108-120, jul-dez de 2018.

RENHE, I. R. T. et al. Obtenção de corante natural azul extraído de frutos de jenipapo. Pesquisa Agropecuária Brasileira, v. 44, n. 6, p. 649-652, jun. 2009, Brasília.

BRASIL. Referencial curricular nacional para as escolas indígenas-RCNEI/Ministério da Educação e do Desporto, Secretaria de Educação Fundamental. - Brasília: MEC/SEF, 1998. Disponível em: < http://www.dominiopublico.gov.br/download/texto/me00 2078.pdf>. Acesso em: agosto de 2015.

STRINGHETA, P. C.; SILVA, P. I. (orgs.). Pigmentos de urucum: extração, reações químicas, usos e aplicações. Viçosa, MG: 2008.

TAUKANE, D. Y. Educação escolar entre os Kurâ- Bakairi. Cuiabá - MT: Edição da Autora, 1999.

ZANON, L. B.; PALHARIN, E.M. A química no ensino fundamental de ciências. Química Nova na escola. v.15, n.18, Nov., 1995.

\footnotetext{
${ }^{\text {i }}$ Doutora e pós-doutora em Educação e Professora do Programa de Pós-Graduação em Educação e do Programa de Pós-Graduação em Ensino de Ciências e Matemática, ambos da Universidade Federal de Sergipe, Grupo de Pesquisa GEPIADDE, membro da coordenação colegiada da NEABI-UFS. edineia.ufs@gmail.com

ii Pós-doutora em Antropologia Social e Doutora Educação. Professora do Programa de Pós-Graduação em Educação da Universidade Federal de Mato Grosso; Coordenadora COEDUC. beleni.grando@gmail.com

iii Mestra em Educação pela Universidade Federal de Mato Grosso. Professora Kurâ-Bakairi, liderança indígena do Instituto Yukamaniru de Apoio às Mulheres Kurâ-Bakairi. dtaukane@uol.com.br

iv Pós-graduado em Educação Escolar Indígena pela Universidade do Estado de Mato Grosso. Professor KurâBakairi, da Escola Estadual Indígena de Educação Básica-Aturua. porohomaiawai@hotmail.com

${ }^{v}$ Mestranda em Ensino de Ciências e Matemática (PPGECIMA/UFS). Bolsista CAPES. Grupo de pesquisa GEPIADDE/UFS. yasminlima.9@gmail.com

vi Resolução n. 5, de 22 de junho de 2012 do Conselho Nacional de Educação, Brasil.

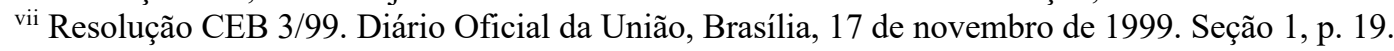


viii Neste texto utilizaremos as definições Ciências e Ciências da Natureza para os conhecimentos, sobretudo, da Química, da Física e da Biologia, abordados nas escolas brasileiras no Ensino Fundamental, mais especificamente na disciplina denominada Ciências Naturais, e no Ensino Médio, na área Ciências da Natureza e suas Tecnologias, com as disciplinas de Química, Física e Biologia.

${ }^{\text {ix }}$ Este trabalho se insere nossa busca por uma construção conjunta, na aprendizagem entre diferentes atores, pesquisadores e pesquisadores/lideranças indígenas, que materializada nessa e em outras narrativas, orais ou escritas, vivências e reflexões teóricas acerca desses e outros conhecimentos produzidos.

${ }^{x}$ A bixina é uma das principais matérias-primas utilizadas na produção de corantes naturais no país, como no colorau usado como corante natural para dar e realçar cor nos alimentos em produtos como colorau, manteiga, margarina, batons, maquiagens, filtros solares, entre outros. $\mathrm{O}$ jenipapo pode ser consumido, enquanto fruto, em sucos, junto com outros alimentos, e em algumas indústrias, como as alimentícias, como fonte de corantes. Esse pigmento juntamente com outros derivados (outras substâncias) pode ser usado na deteç̧ão de impressões digitais a partir de sofisticados meios tecnológicos. 